УДК 339.138

DOI 10.17308/econ.2020.1/2765

\title{
СОСТАВ И СТРУКТУРА \\ МАРКЕТИНГОВЫХ ИНСТРУМЕНТОВ
}

\author{
О. Н. Беленов, И. В. Гончарова
}

\section{Воронежский государственный университет}

Поступила в редакцию 13 ноября 2019 г.

\begin{abstract}
Аннотация: рассмотрены задачи и тенденции совершенствования состава и структуры инструментов маркетинговой деятельности, показывающце необходимость перехода к омниканальному обслуживанию в b2c и b2b сферах.
\end{abstract}

Ключевые слова: цүифровые технологии, комплекс маркетинга, омниканальное обслуживание, бренд, эффективность маркетинговой деятельности.

Abstract: the tasks and trends of improving the composition and structure of marketing tools, showing the need to transition to omnichannel service in $b 2 c$ and $b 2 b$ spheres, are considered.

Key words: digital technology, marketing mix, omnichannel service, brand, marketing effectiveness.

Ориентированность компаний на клиента большинство экспертов считают одним из основных признаков цифровой экономики ${ }^{1}$ [1]. Разрабатываемые продукты и процессы с ориентацией на запросы клиентов - от заказа до доставки и послепродажного обслуживания - новый образ мышления, отражающий способность учиться у потребителей. Наблюдаемая цифровая трансформация маркетинговой деятельности компаний берет свое начало в узкой специализации - интернет-маркетинге. Раньше не все компании полагались на онлайн-каналы коммуникации как главное средство связи с клиентами, у них были сайты и даже интернет-реклама, но не как основа бизнеса. Сейчас цифровые каналы стали влиять на решения о покупке, они рассматриваются потребителями как универсальный источник информации, оптимального подбора, заказов товаров и услуг и как способ свериться с общественным мнением.

Как отмечают исследователи [2], кардинально изменилась структура пользования медиаресурсами. Цифровое взаимодействие бизнеса и покупателей стало основой принятия решений в повседневной жизни, не менее кардинальные сдвиги затронули и маркетинг.
Маркетинговое подразделение остается необходимым элементом управленческой структуры компаний, но его методы, принципы принимаемых решений, влияние на устойчивость бизнеса существенным образом меняются. Вместо планирования отдельных мероприятий, следующих одно за другим, практикуется одновременное непрерывное проведение сразу нескольких программ, ориентированных на целевые микрогруппы. Рекламные трансляции заменяются адресными сообщениями с таким интересным контентом, которым потребители делятся с друзьями. Маркетинг определяет назначение, стратегию бизнеса, становится комплексом организационных рычагов и действий, обеспечивающих осуществление производственных и управленческих функций для достижения целей компании, ее конкурентоспособности и развития.

Основным инструментом совершенствования маркетинговой деятельности являются цифровые технологии, позволяющие использовать углубленный анализ, лучше понимать потребности клиентов, повышать эффективность бизнес-процессов и прибыльность создаваемых активов бизнеса. Обязательно внедрение новых подходов, которые усилят эффекты цифровых технологий. В связи

\footnotetext{
${ }^{1}$ Цифровая экономика означает, что информационные технологии получения, хранения, обработки и передачи больших массивов данных внедряются во все классические отрасли экономики, бизнес и государственное управление.

(С) Беленов О. Н., Гончарова И. В., 2020
} 
с этим цель настоящей статьи - рассмотрение изменений в составе и структуре инструментов маркетинговой деятельности компаний, отвечающих современным тенденциям развития.

В качестве исходных положений, необходимых для выполнения последующего анализа, примем, что маркетинговая деятельность компании является постоянно возобновляемым цикличным процессом, который ориентирован на извлечение максимальной выгоды из имеющихся ресурсов для обеспечения бизнеса конкурентными преимуществами и прибылью. К числу основных задач, решаемых маркетингом, относятся следующие:

- разработка маркетинговых стратегий и связанных с ними планов компании;

- определение критериев и показателей оценки качества, выработка с их использованием объективных мер по его повышению и созданию исключительной потребительской ценности бизнеса;

- обеспечение целенаправленной обработки информации о текущем состоянии рынков, потребителей, конкурентов в поддержание достигнутых конкурентных преимуществ;

- создание потенциала для совершенствования процесса принятия решений по адаптации к изменяющимся внешним условиям, включая воздействия на рыночную среду (а не просто приспособления к ней);

- создание отношений с партнерами и потребителями, формирование сильных брендов, предоставление рыночных предложений, продвижение ценности;

- оценка эффективности маркетинговой деятельности компании.

Рассмотренные общие положения маркетинговой деятельности компании характеризуют целостный маркетинг, который признает, что выработка идей, стратегическое планирование, разработка и внедрение программ осуществляются в комплексе с учетом их взаимозависимости и в масштабах всей компании. Цифровые технологии позволяют учитывать всеохватывающие факторы влияния на потребителей и привлекать широкий арсенал средств целенаправленного воздействия на целевые группы. Успех современного маркетинга во многом зависит от цифровых каналов связи и способов работы с клиентами.

Последние годы характеризуются стремительным развитием многоканальности и омниканальности в b2c и даже b2b cферах [3-5]. Несмотря на схожесть данных понятий, оба подразумевают несколько каналов продаж и обслуживания, вклю- чая интернет, мобильную связь, физические точки продаж, в них есть и существенная разница. Омниканальность означает возможность для клиента начать транзакцию в одном канале, продолжить в другом, а завершить в третьем. Омниканальность предполагает, что компания должна сформировать единую систему обслуживания клиентов во всех онлайн- и офлайн- каналах и на всех этапах взаимодействия. Необходимо принять стратегические решения относительно того, какая структура каналов лучше всего подходит для целевой аудитории, как совместить их в рамках сквозной системы обслуживания. (Например, нужно ли энергетическому предприятию присутствовать на сайтах сравнения цен?)

Из-за стремительного увеличения количества каналов и технологий в маркетинге появился широкий спектр новых направлений деятельности. Так, требования международных профессиональных стандартов СIM (The Chartered Institute of Marketing) [6] обязывают маркетологов всех уровней и специализаций рационально разделять стратегические и тактические инструменты в продвижении продуктов, брендов, компаний, предоставляя ценность потребителям всеми возможными способами. Значительные перемены в маркетинговом миксе были представлены CIM еще в 2016 г. и могут быть схематично проиллюстированы (рисунок).

Как показано на рисунке, расширение состава средств маркетинговой деятельности происходит за счет учета всех возможных сторон контакта с потребителями в b2c и b2b сферах. В центре находится маркетинговая стратегия, от нее, как лучи, расходятся направления деятельности.

Стратегия включает ориентацию на выгоду для клиентов, принятие решений на основе данных и аналитику (маркетинговые исследования), постоянную доработку на основе быстрой обратной связи и сознательное экспериментирование с целью поиска новых решений для укрепления позиционирования бизнеса. В стратегии, наряду с уровнем качества товаров и услуг, ценообразованием, системой сбыта, комплексом продвижения (модель «4Р»), в полной мере используется привлечение широкого арсенала средств, обеспечивающих прогнозирование вероятной рентабельности маркетинговых действий. Более эффективное планирование на основе больших массивов данных и продвинутой аналитики с использованием систем машинного обучения, обладающих искусственным интеллектом, позволяет оптимизировать каждый этап создания стоимости для бизнеса. 


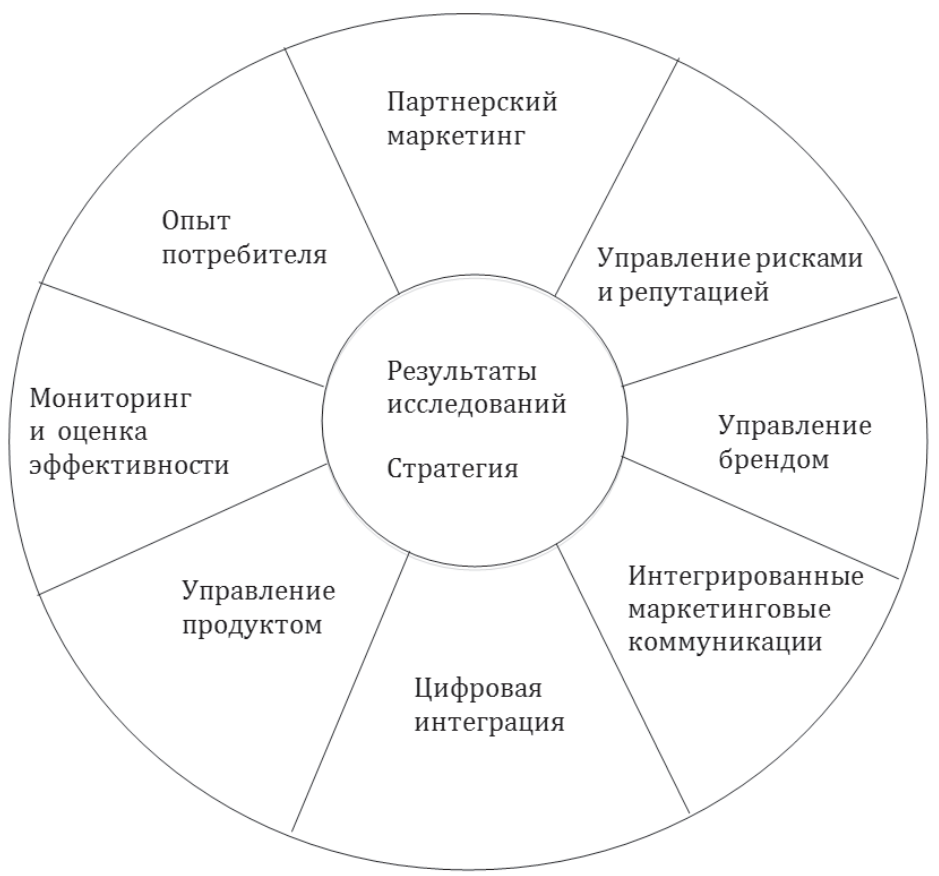

Рисунок. Новые направления в маркетинговой деятельности, по данным [6]

В свою очередь возможность охвата все большего числа составляющих бизнеса, оказывающих целенаправленное воздействие на вовлеченность и лояльность при создании ценности для целевых групп, является основой постоянного совершенствования маркетинговых инструментов. Расширение состава направлений деятельности за счет учета всех сторон контакта с клиентами становится одним из неизбежных приемов ведения конкурентной борьбы. Современный комплекс маркетинга состоит из следующих направлений: опыт потребителя, цифровая интеграция, управление продуктом, интегрированные маркетинговые коммуникации, управление брендом, управление рисками и репутацией, партнерский маркетинг, мониторинг и оценка эффективности, их подробное описание представлено в таблице.

Следует отметить, что развитие цифровых технологий вынуждает бизнес быть более открытым, а превращение в объект продажи обещаний бренда и репутации бизнеса способствует разделению уровней управления: продуктом, брендом и компанией в целом. Это позволяет развивать разные приемы и оптимизировать методы менеджмента.

На современном этапе существует ограниченное количество конкурентных преимуществ, которые каждый бизнес может сохранить на протяжении длительного времени, обеспечивая прибыльность и стратегическое превосходство. Бренд один из таких ресурсов, создающий барьеры для конкурентов, укрепляющий репутацию компании, обеспечивающий время для реагирования на угрозы, сокращающий затраты на сбыт. Поэтому важнейшей задачей каждого бизнеса является рациональное использование брендов.

Бренд приобретает известность благодаря созданию необходимых потребителям продуктов и формирует свой собственный способ коммуникации на основе опыта использования товаров и услуг, когда источником рекламной информации становятся удовлетворенные клиенты. При разработке продуктов активно применяется концепция минимально жизнеспособного продукта (MVP) [7], особенно в отношении процессов взаимодействия с клиентами. Например, в автомобилях Tesla постоянно совершенствуются характеристики и функциональные возможности даже после продажи, владельцам предлагаются обновления программного обеспечения. Также становится важным новый продукт, запускаемый под существующим брендом, поскольку постоянные инновации создают ареол актуальности бренда для потребителей. Бренды не существуют без управленческой поддержки бизнеса, и невозможно построить бренд, не создав компанию. По сути, бренд представляет собой систему материальных и нематериальных ценностей, предлагаемых покупателю, которые, с одной стороны, поддерживаются продуктом, а с другой - бизнес-процессами компании. 
Состав и содержание маркетинговых инструментов

\begin{tabular}{|c|c|c|}
\hline № & Наименование & Содержание \\
\hline 1 & Опыт потребителя & $\begin{array}{l}\text { Каналы взаимодействия с потребителями. Сбор данных и обратная связь (источники, } \\
\text { оценка, критерии выбора). Определение того, как должна быть построена работа с } \\
\text { клиентами для достижения корпоративных целей и защиты интересов потребителей. } \\
\text { Путь потребителя и моделирование клиентского опыта (СJM). Маркетинговые про- } \\
\text { граммы снижения потребительских усилий }\end{array}$ \\
\hline 2 & $\begin{array}{l}\text { Цифровая } \\
\text { интеграция }\end{array}$ & $\begin{array}{l}\text { Внедрение цифровых изменений (улучшений) в маркетинговую деятельность исходя из } \\
\text { потребностей клиентов. Маркетинговые программы по работе с сайтом и представитель- } \\
\text { ством в интернете. Привлечение потребителей: генерация новых потребителей (лидов), } \\
\text { монетизация существующих клиентов, вовлечение в сообщества бренда }\end{array}$ \\
\hline 3 & $\begin{array}{l}\text { Управление } \\
\text { продуктом }\end{array}$ & $\begin{array}{l}\text { Разработка ценностного предложения и его продвижение на рынок. Маркетинг про- } \\
\text { дукта (как создавать продукты, которые захотят покупать?). Управление проектами, } \\
\text { связанными с обеспечением ценностного предложения и портфелем товаров и услуг }\end{array}$ \\
\hline 4 & $\begin{array}{l}\text { Интегрированные } \\
\text { маркетинговые } \\
\text { коммуникации }\end{array}$ & $\begin{array}{l}\text { Интеграция маркетинговых кампаний со стратегией бизнеса и комплексное исполь- } \\
\text { зование онлайн- и офлайн- коммуникаций. Планирование, разработка и реализация } \\
\text { интегрированных коммуникаций для установления связи со всеми стейкхолдерами }\end{array}$ \\
\hline 5 & $\begin{array}{l}\text { Управление } \\
\text { брендом }\end{array}$ & $\begin{array}{l}\text { Управление эффективностью бренда как ресурсом бизнеса. Предпочтительное позици- } \\
\text { онирование бренда. Источники формирования капитала бренда. Управление портфелем } \\
\text { брендов. Киберустойчивость брендов. Продвижение и формирование сообществ бренда }\end{array}$ \\
\hline 6 & $\begin{array}{l}\text { Управление } \\
\text { рисками } \\
\text { и репутацией }\end{array}$ & $\begin{array}{l}\text { Управление корпоративной репутацией, в том числе онлайн. Контроль влияния рисков, } \\
\text { государственного воздействия, с помощью эффективного мониторинга и соблюдения } \\
\text { соответствующих законодательств. Формирование корпоративной репутации при уста- } \\
\text { новлении согласованности между персоналом, бизнес-процессами и брендом }\end{array}$ \\
\hline 7 & $\begin{array}{l}\text { Партнерский } \\
\text { маркетинг }\end{array}$ & $\begin{array}{l}\text { Формирование партнерских маркетинговых каналов с целью удовлетворения потреб- } \\
\text { ностей клиентов и получения дополнительной прибыли бизнесом. Сеть партнерских } \\
\text { программ. Маркетинговые кампании по объединению всех участников рынка для обе- } \\
\text { спечения партнерства }\end{array}$ \\
\hline 8 & $\begin{array}{l}\text { Мониторинг } \\
\text { и оценка } \\
\text { эффективности }\end{array}$ & $\begin{array}{l}\text { Определение соответствующих показателей, необходимых для постоянного отслеживания } \\
\text { всех маркетинговых действий, создаваемых компанией и клиентами. Оценка эффективно- } \\
\text { сти маркетинговой деятельности. Мониторинг цифровой и социальной репутации. Исполь- } \\
\text { зование аналитики (полученные данные и аналитические материалы), чтобы объяснить } \\
\text { успех или неудачу маркетинговой деятельности и для достижения улучшений в будущем }\end{array}$ \\
\hline
\end{tabular}

Переход к омниканальному обслуживанию обеспечивает развитие не только разных уровней управления в маркетинге, но и новейших направлений деятельности. Партнерский маркетинг осуществляет автоматизированное взаимодействие с целевыми группами через партнеров и сеть партнерских программ.

Согласно данным глобального института McKinsey [8] отличительными особенностями мировых лидеров в области омниканального обслуживания являются:

- сфокусированность на клиенте независимо от каналов обслуживания для обеспечения бесшовного клиентского опыта при переключении между каналами;

- непрерывные действия и инвестиции в приоритетные направления для укрепления конкурентных преимуществ;

- повышение качества принимаемых решений за счет аналитики на базе данных из разных кана- лов и применения комплексного интерактивного подхода test-and-learn (от испытаний к знаниям);

- мотивация к взаимодействию сотрудников, отвечающих за разные каналы;

- оптимизация бизнес-процессов и инфраструктуры, включая торговые точки, прикладные программные интерфейсы, которые обеспечивают взаимодействие старых и новых систем для уменьшения «конфликтов» между каналами.

В целом для стратегических и операционных процессов маркетинговой деятельности должны быть четко описаны правила игры во всех каналах. Например, определена модель ценообразования в офлайн- и онлайн- каналах или принято решение, как должны сочетаться распродажи, проходящие в одно время, в физических магазинах и в интернете. Успешные российские компании, включая онлайн-гипермаркеты (Ozon, Wildberris) и маркетплейсы (Tmall, Беру!, Goods), бурно развивают автоматизацию процессов. Наиболее агрессивная конку- 
ренция происходит между крупнейшими игроками офлайн, активно инвестирующими в онлайн (X5 Retail Group, М.Видео) и онлайн-компаниями (Яндекс и Mail.ru), которые в рамках партнерств с лидером банковского рынка (Сбербанк) формируют комплексные цифровые платформы.

Таким образом, на основе проведенного анализа можно сделать следующие выводы.

1. Динамичность глобальной конкуренции, изменения в покупательском поведении и развитие цифровых технологий являются основой движущей

\section{ЛИТЕРАТУРА}

1. AHО «Цифровая экономика». - URL: https://dataeconomy.ru/science

2. Министерство цифрового развития связи и массовых коммуникаций Российской Федерации, официальный сайт. - URL: https://digital.gov.ru/ru/activity/directions/878/

3. Кулагин B. Digital@Scale : Настольная книга по цифровизации бизнеса / В. Кулагин, А. Сухаревски, Ю. Мефферт. - М. : Интеллектуальная литература, 2019. - 293 c.

4. Роулс Д. Мобильный маркетинг : мобильные технологии - революция в маркетинге, коммуникациях и рекламе / Дэниел Роулс. - М. : Олимп-Бизнес, 2019. - 296 с.

Воронежский государственный университет

Беленов О. Н., доктор экономических наук, профессор, декан факультета международных отномений

E-mail:belenov@vsu.ru

Тел.: +7 (473) 220-88-69

Гончарова И. В., кандидат экономических наук, доцент кафедры экономики, маркетинга и коммеричи экономического факультета

E-mail: goncharova@econ.vsu.ru

тел.: +7 (473) 251-74-99 силы постоянного увеличения количества и совершенствования маркетинговых инструментов.

2. Структура и состав маркетинговых инструментов принципиально меняются, вынуждая компании ориентироваться на запросы клиентов и переходить к омниканальному обслуживанию в b2c и b2b cферах. Задача оптимизации маркетингового микса становится одной из важных для компаний, поскольку прибыль формируется за счет подходов, основанных на постоянной обратной связи с клиентами, при разработки индивидуальных предложений.

5. Бринкер C. Agile-маркетинг. Хакерские практики для эффективного бизнеса / Скотт Бринкер. - М. : Манн, Иванов и Фербер, 2019. - 272 с.

6. Международные профессиональные стандарты в области маркетинга (The Chartered Institute of Marketing (CIM)). - URL: https://www.cim.co.uk/

7. Херф C. Как создать продукт, который полюбят. Опыт успешных менеджеров и дизайнеров / Скотт Херф. - М. : Манн, Иванов и Фербер, 2019. - 288 с.

8. Цифровая Россия : новая реальность // Отчет McKinsey\&Company, июль 2017 г. - URL: https://www. mckinsey.com/ru/our-insights

\section{Voronezh State University}

Belenov O. N., Doctor of Economic Sciences, Professor, Dean of the International Relations Faculty E-mail:belenov@vsu.ru

Tel.: +7 (473) 220-88-69

Goncharova I. V., PhD of Economy, Associate Professor of Economics, Marketing and Commerce Department

E-mail: goncharova@econ.vsu.ru

Tel.: +7 (473) 251-74-99 